\title{
Synthesis of some biologically active monoazo disperse dyes derived from nicotinic acid derivatives under microwave irradiation for dyeing polyester fabrics
}

\author{
Fawzia Al-Qalaf a, Khaledah Almohammad a, Morsy Ahmed El-Apasery b,*, and Huda Mahmoud c \\ a Applied Science Department, College of Technological Studies, Public Authority for Applied Education and Training, Safat, 70654, Kuwait \\ b Dyeing, Printing and Textile Auxiliaries Department, Textile Research Division, National Research Centre, 12622 Dokki, Giza, Egypt \\ c Department of Biological Sciences, Faculty of Science, Kuwait University, Safat 13060, Kuwait \\ ${ }^{*}$ Corresponding author at: Dyeing, Printing and Textile Auxiliaries Department, Textile Research Division, National Research Centre, 12622 Dokki, Giza, Egypt. \\ Tel.: +2.02.3371718; fax: +2.02.3370931. E-mail address: elapaserym@yahoo.com (M. A. El-Apasery).
}

\begin{tabular}{l} 
ARTICLE INFORMATION \\
\hline Received: 24 March 2013 \\
Received in revised form: 23 April 2013 \\
Accepted: 23 April 2013 \\
Online: 30 September 2013 \\
KEYWORDS \\
\hline Disperse dyes \\
Polyester fabrics \\
Biological activity \\
Arylazonicotinates \\
Fastness properties \\
Microwave irradiation
\end{tabular}

\section{Introduction}

Disperse dyes are organic colors having less water solubility and are applied in colloidal aqueous dispersions to hydrophobic textile fabrics in which the dyes literally dissolve and produce desired coloration. The development of disperse dyes is due to significant increase in the world production of polyester fabrics as compared to other fabrics. A monoazo dye with a heterocyclic system would be considered as a useful class of disperse dyes [1-5]. Derivatives of nicotinates have a long history of use as heterocyclic components for various disperse dyes [6-8]. Moreover, they have been proven to constitute the active part of several biologically active compounds [9-12]. Several studies have shown that microwave irradiation is a beneficial method to promote diverse organic transformations that occur in remarkably reduced reaction times and improved yields [1]. As an extension of our previous studies [13] on the synthesis of a variety of 2-amino and 2hydroxy-6-substituted-5-arylazonicotinates disperse dyes under traditional heating way. In this article, we report a new synthesis of theses dyes under microwave irradiation and their application for dyeing polyester fabrics. Also, the present study was undertaken to investigate the biological activity of the synthesized disperse dyes against Bacillus subtilus and Staphylococcus auerus (Gram-positive bacteria), Escherichia coli and Pseudomonas aeruginosa (Gram-negative bacteria), and Candida albicans (Yeast).

\section{Experimental}

2.1. Instrumentation
Melting points were recorded on a Gallenkamp apparatus. IR spectra were recorded using $\mathrm{KBr}$ pellets on a JASCO FTIR$6300 \mathrm{FT}$-IR spectrophotometer. ${ }^{1 \mathrm{H}}$ - and ${ }^{13} \mathrm{C}$-NMR spectra were recorded on Bruker DPX $400 \mathrm{MHz}$ super-conducting NMR spectrometers with proton spectra measured at $400 \mathrm{MHz}$ and carbon spectra at $100 \mathrm{MHz}$, respectively. Mass spectra were measured on a high resolution GC/MS DFS-Thermo. Microanalyses were performed on Elementar-Vario Micro cube Analyzer. Compounds 2a-c are prepared according to our previous work $[13,14]$.

\subsection{Ethyl 2-amino-5-((4-chlorophenyl)diazenyl)-6- (naphthalen-2-yl)nicotinate (6)}

A mixture of the arylhydrazonal $2 \mathbf{a},(10 \mathrm{mmol})$, ethyl cyanoacetate $(1.2 \mathrm{~g}, 10 \mathrm{mmol})$ and ammonium acetate $(2 \mathrm{~g})$ in acetic acid $(2 \mathrm{~mL})$ were irradiated by focused microwave at 180 ${ }^{\circ} \mathrm{C}$ for $30 \mathrm{sec}$ (monitored by TLC using 1:1 (v:v); EtOAc:petroleum ether as eluent). The build-up of pressure in the closed reaction vessel was carefully monitored. After the irradiation, the reaction tube was cooled with high-pressure air through an inbuilt system in the instrument until the temperature had fallen below $50{ }^{\circ} \mathrm{C}$. The mixtures were cooled and then poured into ice-water. The formed precipitate was collected by filtration washed with water and recrystallized from ethanol (Scheme 1). Color: Orange. Yield: 86\%. (3.71 g). M.p.: $90^{\circ} \mathrm{C}$ (Lit. [13] Yield: $77 \%$. M.p.: $\left.89-90^{\circ} \mathrm{C}\right)$. FT-IR $(\mathrm{KBr} \mathrm{cm}$ 1): 3444, $4350\left(\mathrm{NH}_{2}\right), 1743$ (CO). ${ }^{1} \mathrm{H}$ NMR ( $400 \mathrm{MHz}, \mathrm{DMSO}-d_{6}$, $\delta$, ppm): $1.37\left(\mathrm{t}, 3 \mathrm{H}, J=7.4 \mathrm{~Hz}, \mathrm{CH}_{3}\right), 4.39\left(\mathrm{q}, 2 \mathrm{H}, J=7.4 \mathrm{~Hz}, \mathrm{CH}_{2}\right)$, 7.56-7.62 (m, 4H, Ar-H), 7.72 (d, $2 \mathrm{H}, J=8.0 \mathrm{~Hz}, \mathrm{Ar}-\mathrm{H}), 7.93-8.02$ (m, 4H, Ar-H), $8.12\left(\mathrm{br}, 2 \mathrm{H}, \mathrm{NH}_{2}\right), 8.35(\mathrm{~s}, 1 \mathrm{H}, \mathrm{Ar}-\mathrm{H}), 8.62(\mathrm{~s}, 1 \mathrm{H}$, pyridine $\mathrm{H})$.

European Journal of Chemistry 


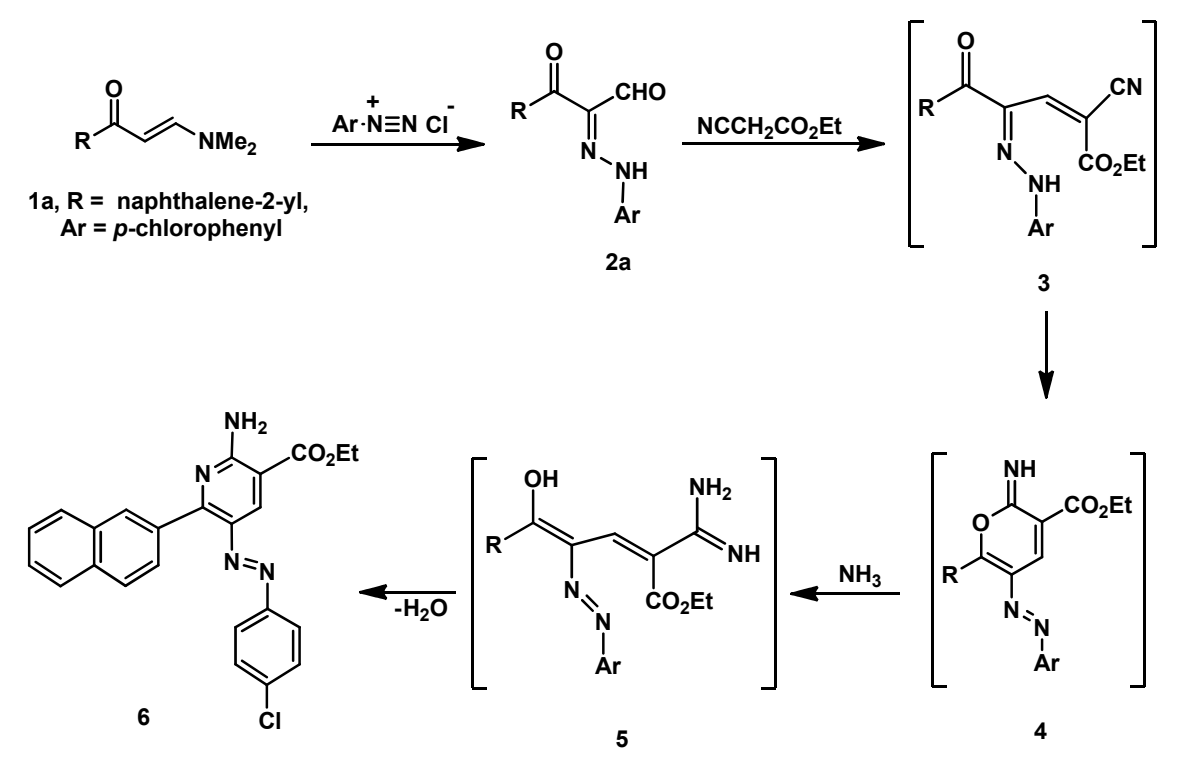

Scheme 1

${ }^{13} \mathrm{C}$ NMR (100 MHz, DMSO- $\left.d_{6}, \delta, \mathrm{ppm}\right): 14.2\left(\mathrm{CH}_{3}\right), 61.2$ $\left(\mathrm{CH}_{2}\right), 105.1,124.0,126.5,126.6,127.2,127.4,127.5,128.2$, 128.6, 129.4, 129.5, 131.0, 132.2, 133.1, 134.6, 134.9, 136.6, 150.9, 159.8, 166.2 (CO). MS (m/z, (\%)): $430\left(\mathrm{M}^{+}, 100\right), 431$ $\left(\mathrm{M}^{++1}, 55\right) . \lambda_{\max }(\mathrm{DMF}, \mathrm{nm}): 377$. Anal. calcd. for $\mathrm{C}_{24} \mathrm{H}_{19} \mathrm{ClN}_{4} \mathrm{O}_{2}$ : C, 66.90; H, 4.44; N, 13.00. Found: C, 66.88; H, 4.38; N, 13.11\%.

\subsection{General procedure for the preparation of compounds $(7 a, b)$}

Independent mixtures of compound $\mathbf{2 b}$ or $\mathbf{2 c}(0.01 \mathrm{~mol})$, ethyl cyanoacetate $(0.01 \mathrm{~mol})$, and ammonium acetate $(0.5 \mathrm{~g})$ in acetic acid $(2 \mathrm{~mL})$ were irradiated by focused microwave at $180{ }^{\circ} \mathrm{C}$ for 30 sec (monitored by TLC using 1:1(v:v); EtOAc:petroleum ether as eluent). The build-up of pressure in the closed reaction vessel was carefully monitored. After the irradiation, the reaction tube was cooled with high-pressure air through an inbuilt system in the instrument until the temperature had fallen below $50^{\circ} \mathrm{C}$. The mixtures were cooled and then poured into ice-water. The solids that formed were collected by using filtration and crystallized from ethanol to give compound $\mathbf{7 a}, \mathbf{b}$ (Scheme 2).

Ethyl 2-hydroxy-5-(phenyldiazenyl)-6-(1H-pyrrol-2-yl)nicotinate (7a): Color: Dark brown. Yield: 72\%. (2.43 g). M.p.: 203-205 ${ }^{\circ} \mathrm{C}$ (Lit. [13] Yield: 60\%. M.p: 202-204 ${ }^{\circ} \mathrm{C}$ ). FT-IR (KBr $\mathrm{cm}^{-1}$ ): $3300(\mathrm{OH}), 3064(\mathrm{NH}), 1598(\mathrm{CO}) .{ }^{1} \mathrm{H}$ NMR $(400 \mathrm{MHz}$, DMSO- $\left.d_{6}, \delta, \mathrm{ppm}\right): 1.30\left(\mathrm{t}, 3 \mathrm{H}, J=7.2 \mathrm{~Hz}, \mathrm{CH}_{3}\right), 4.31(\mathrm{q}, 2 \mathrm{H}, J=$ $\left.7.2 \mathrm{~Hz}, \mathrm{CH}_{2}\right), 7.10-7.77(\mathrm{~m}, 8 \mathrm{H}, \mathrm{Ar}-\mathrm{H}), 8.31$ (s, $1 \mathrm{H}$, pyridyl-H); $11.89\left(\mathrm{~s}, 1 \mathrm{H}, \mathrm{NH}, \mathrm{D}_{2} \mathrm{O}\right.$ exchangeable), $12.18\left(\mathrm{~s}, 1 \mathrm{H}, \mathrm{OH}, \mathrm{D}_{2} \mathrm{O}\right.$ exchangeable). ${ }^{13} \mathrm{C}$ NMR $\left(100 \mathrm{MHz}, \mathrm{DMSO}-d_{6}, \delta, \mathrm{ppm}\right): 13.9$ $\left(\mathrm{CH}_{3}\right), 61.7\left(\mathrm{CH}_{2}\right), 110.9,117.2,121.2,123.0,126.0,127.5$, 128.8, 129.0, 130.9, 131.4, 141.3, 141.8, 175.0, 176.9 (CO). MS $(\mathrm{m} / z,(\%)): 337\left([\mathrm{M}+1]^{+}, 95\right) . \lambda_{\max }(\mathrm{DMF}, \mathrm{nm}): 312$. Anal. calcd. for $\mathrm{C}_{18} \mathrm{H}_{16} \mathrm{~N}_{4} \mathrm{O}_{3}$ : C, 64.28; $\mathrm{H}, 4.79 ; \mathrm{N}, 16.66$. Found: $\mathrm{C}, 63.97 ; \mathrm{H}$, 4.63; $\mathrm{N}, 16.44 \%$. HRMS (EI, $m / z$ ) for $\mathrm{C}_{18} \mathrm{H}_{16} \mathrm{~N}_{4} \mathrm{O}_{3}$; calcd. 336.1216; found: $336.1216 \%$.

Ethyl 2-hydroxy-6-(pyrazin-2-yl)-5-(p-tolyldiazenyl)nicotinate (7b): Color: Brown powder. Yield: $71 \%$ (2.58 g). M.p.: $>300{ }^{\circ} \mathrm{C}$ (Lit. [13] Yield: $68 \%$. M.p: $>300{ }^{\circ} \mathrm{C}$ ). FT-IR (KBr $\left.\mathrm{cm}^{-1}\right): 3312(\mathrm{OH}), 1610(\mathrm{CO}) .{ }^{1} \mathrm{H}$ NMR (400 MHz, DMSO-d $6, \delta$, ppm): $1.30\left(\mathrm{t}, 3 \mathrm{H}, J=7.2 \mathrm{~Hz}, \mathrm{CH}_{3}\right), 2.33\left(\mathrm{~s}, 3 \mathrm{H}, \mathrm{CH}_{3}\right), 4.23(\mathrm{q}, 2 \mathrm{H}$, $\left.J=7.2 \mathrm{~Hz}, \mathrm{CH}_{2}\right), 7.06-7.77(\mathrm{~m}, 6 \mathrm{H}, \mathrm{Ar}-\mathrm{H}), 8.16(\mathrm{~s}, 1 \mathrm{H}, \mathrm{Ar}-\mathrm{H}), 9.04$ (s, $1 \mathrm{H}$, arom-H), $12.00\left(\mathrm{~s}, 1 \mathrm{H}, \mathrm{OH}, \mathrm{D}_{2} \mathrm{O}\right.$ exchangeable). ${ }^{13} \mathrm{C}$ NMR
(100 MHz, DMSO- $\left.d_{6}, \delta, \mathrm{ppm}\right): 13.9\left(\mathrm{CH}_{3}\right), 20.7\left(\mathrm{CH}_{3}\right), 55.8\left(\mathrm{CH}_{2}\right)$, 112.6, 117.1, 121.3, 123.2, 125.6, 127.5, 128.8, 129.2, 132.4, 135.0, 139.9, 157.5, 161.9, 165.7 (CO). MS ( $m / z,(\%)): 363\left(\mathrm{M}^{+}\right.$, 9). $\lambda_{\max }\left(\mathrm{DMF}, \mathrm{nm}\right.$ ): 308 . Anal. calcd. for $\mathrm{C}_{19} \mathrm{H}_{17} \mathrm{~N}_{5} \mathrm{O}_{3}: \mathrm{C}, 62.80 ; \mathrm{H}$, 4.72; N, 19.27. Found: C, $62.55 ; \mathrm{H}, 4.65 ; \mathrm{N}, 19.16 \%$.

\subsection{High temperature dyeing method (HT)}

\subsubsection{Materials}

Scoured and bleached polyester 100\% (150 $130 \mathrm{~g} / \mathrm{m}^{2}, 70 / 2$ denier) was obtained from El-Shourbagy Co., Egypt. The fabric was treated before dyeing with a solution containing non-ionic detergent (Sera Wash M-RK, $5 \mathrm{~g} / \mathrm{L}$ ) and sodium carbonate $(2$ $\mathrm{g} / \mathrm{L}$ ) in a ratio of $50: 1$ at $60{ }^{\circ} \mathrm{C}$ for $30 \mathrm{~min}$, and then thoroughly washed with water and air dried at room temperature.

\subsubsection{Dyeing}

The dye baths were prepared from the dye $(2 \%$ weight of fabric) to a final liquor of 50:1 (w:w). The $\mathrm{pH}$ value of the bath was adjusted to 4.5-5.0 with acetic acid (10\%) in the presence of a 1:1 ratio of the dispersing agent (Sera Gal P-LP). The temperature was raised to $130{ }^{\circ} \mathrm{C}$ at the rate of $7{ }^{\circ} \mathrm{C} / \mathrm{min}$, and dyeing continued for $60 \mathrm{~min}$. After dyeing, the fabrics were thoroughly washed and then subjected to a surface reduction cleaning $[(2 \mathrm{~g} \mathrm{NaOH}+2$ g sodium hydrosulphite $) / \mathrm{L}]$. The samples were heated in this solution for $30 \mathrm{~min}$. at $85{ }^{\circ} \mathrm{C}$ and then thoroughly washed and air-dried.

\subsection{Color measurements and analyses}

\subsubsection{Color measurements}

The colorimetric parameters (Table 1) of the dyed polyester fabrics were determined on a reflectance spectrophotometer. The color yields of the dyed samples were determined by using the light reflectance technique performed on UV/VIS Spectrophotometer. The color strengths, expressed as $\mathrm{K} / \mathrm{S}$ values, were determined by applying the Kubelka-Mink [15] equation (1) as follows:

$K / S=\left[(1-R)^{2} / 2 R\right]-\left[\left(1-R_{\mathrm{o}}\right)^{2} / 2 R_{\mathrm{o}}\right]$ 


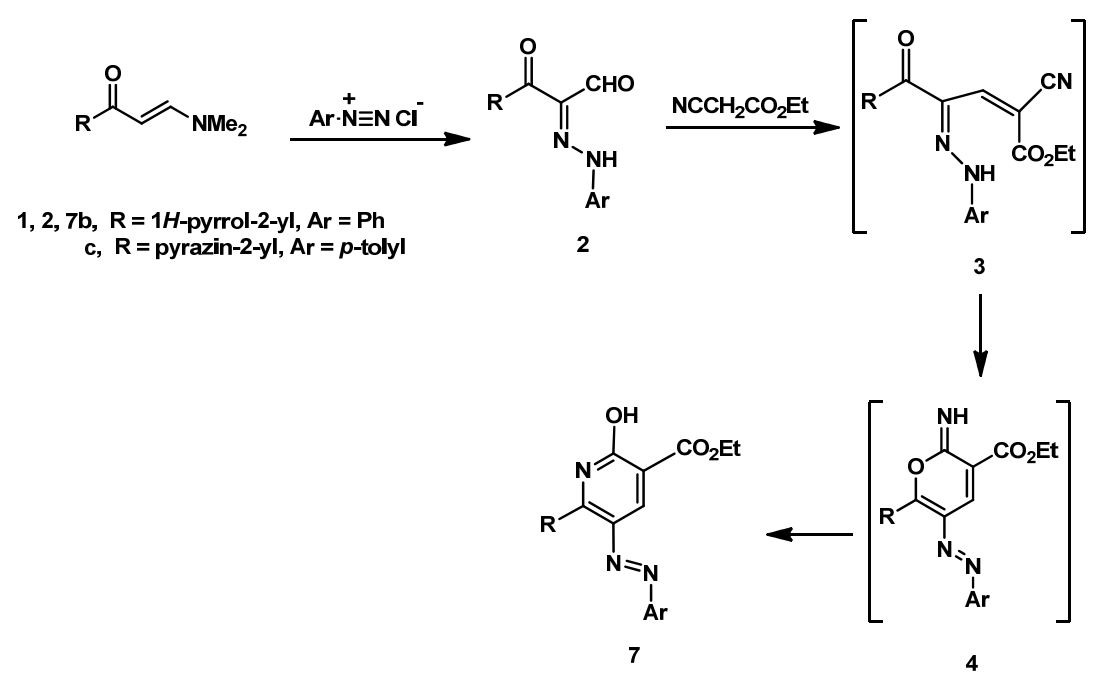

Scheme 2

where $R=$ decimal fraction of the reflectance of the dyed fabric; $R_{o}=$ decimal fraction of the reflectance of the undyed fabric; $K=$ absorption coefficient; $S=$ scattering coefficient.

\subsubsection{Fastness tests}

\subsubsection{Fastness to washing}

After washing using $5 \mathrm{~g} / \mathrm{L}$ of the nonionic detergent Hostapal CV and $2 \mathrm{~g} / \mathrm{L}$ of sodium carbonate at $80^{\circ} \mathrm{C}$ for $15 \mathrm{~min}$, the dyed fabrics were tested by using ISO standard methods [16]. A specimen of dyed polyester fabric was stitched between two pieces of undyed cotton and wool fabrics, all of equal length, and then washed at $95{ }^{\circ} \mathrm{C}$ for $30 \mathrm{~min}$. The staining on the undyed adjacent fabrics was assessed according to the following gray scale: 1-poor, 2-fair, 3-moderate, 4-good, 5excellent.

\subsubsection{Fastness to perspiration}

The samples were prepared by stitching a piece of dyed polyester fabric between two pieces of cotton and wool fabrics, all of equal length, and then immersed in the acid or alkaline solution for $30 \mathrm{~min}$. The staining on the undyed adjacent fabrics was assessed according to the following gray scale: 1-poor, 2fair, 3-moderate, 4-ood, 5-excellent. The acid solution $(\mathrm{pH}=$ 4.5) contains sodium chloride $(10 \mathrm{~g} / \mathrm{L})$, sodium dihydrogen orthophosphate $(1 \mathrm{~g} / \mathrm{L})$ and histidine monohydrochloride $(0.25$ $\mathrm{g} / \mathrm{L})$. The alkaline solution $(\mathrm{pH}=8.7)$ contains sodium chloride $(10 \mathrm{~g} / \mathrm{L})$, disodium orthophosphate $(1 \mathrm{~g} / \mathrm{L})$ and histidine monohydrochloride $(0.25 \mathrm{~g} / \mathrm{L})$.

\subsubsection{Fastness to light}

Light fastness was determined by exposing the dyed polyester on a Xenotest 150 (Original Hanau, chamber temperature: $25-30{ }^{\circ} \mathrm{C}$, black panel temperature: $60^{\circ} \mathrm{C}$, relative humidity: 50-60\%, dark glass UV filter system) for $40 \mathrm{~h}$. The changes in color were assessed according to the following blue scale: 1-poor, 3-moderate, 4-good, 6-very good, 8-excellent.

\subsection{Antimicrobial activities test}

The antimicrobial activities of arylhydrazonals and disperse dyes were tested using Agar-well diffusion technique [17], against five different microbial cultures. Pure cultures of
Bacillus subtilus and Staphylococcus auerus (Gram-positive bacteria), Escherichia coli and Pseudomonas aeruginosa (Gramnegative bacteria), and Candida albicans (Yeast) were involved in the test. An aliquot of $0.1 \mathrm{~mL}$ of each bacterial strain was inoculated and spread on nutrient agar (NA) while $0.1 \mathrm{~mL}$ of the yeast was spread on potato dextrose agar (PDA). The inoculated plates were supplied with $100 \mu \mathrm{L}$ of each of the tested arylhydrazonals and disperse dyes with a total final concentration of $100 \mathrm{mg} / \mathrm{mL}$. The arylhydrazonals and disperse dyes were included in $4 \mathrm{~mm}$ wells produced by sterile cork borer. The NA plates were incubated at $37{ }^{\circ} \mathrm{C}$ for 24 hours while PDA plates were incubated at $25{ }^{\circ} \mathrm{C}$ for $24-48 \mathrm{~h}$. The zones of inhibition around the wells were determined and the average based on 3 replicas was recorded. Cycloheximide and Ampicillin both used as references in the experiment where Cycloheximide known to inhibit eukaryotic organisms while Ampicillin inhibit prokaryotes. Picture were taken for some of the plates after 24,72 and $120 \mathrm{~h}$ using digital camera to determine the nature of the chemicals if they were cytolytic or cytostatic

\section{Results and discussion}

Recently we have reported the synthesis of 2-amino- and 2hydroxy-6-substituted-5-arylazonicotinates dyes [13]. Herein, in an attempt to improve and facilitate the synthesis of these disperse dyes, we report a new strategy for the preparation of these disperse dyes in better yields by condensing of arylhydrazonals $\mathbf{2 a - c}$ with ethyl cyanoacetate under microwave irradiation as an energy source. We observed that reaction of 2a with ethyl cyanoacetate in presence of excess of ammonium acetate in a focused microwave oven at $180{ }^{\circ} \mathrm{C}$ for $30 \mathrm{sec}$. 2aminoarylazonicotinate disperse dye $\mathbf{6}$ is produced. It is believed that the pathways for this process involve initial reaction of $2 \mathbf{a}$ with ethyl cyanoacetate to yield the hydrazonoenone 3 that then cyclizes to generate the pyran-imine 4 . In the presence of a high concentration of ammonium acetate, pyranimine $\mathbf{4}$ participates in ring opening to yield amidine $\mathbf{5}$ that then cyclizes followed by water elimination to yield $\mathbf{6}$ (Scheme $1)$.

In contrast, when the condensation reaction of $\mathbf{2 b} \mathbf{b} \mathbf{c}$ with ethyl cyanoacetate in the presence of a catalytic amount of ammonium acetate and a few drops of acetic acid by heating in a focused microwave oven at $180{ }^{\circ} \mathrm{C}$ for $30 \mathrm{sec}$. leads to yield the 2-hydroxy-6-substituted-5-aryl azonicotinate 7a,b. 
Table 1. Optical measurements of the synthesized monoazo disperse dyes on the polyester fabrics $\dagger$.

\begin{tabular}{|c|c|c|c|c|c|c|}
\hline Dye No & $\boldsymbol{K} / \boldsymbol{S}$ at $\left(\lambda_{\max }\right)$ & $L^{*}$ & $a^{*}$ & $b^{*}$ & $C^{*}$ & $\boldsymbol{h}$ \\
\hline 6 & $17.50(370)$ & 60.72 & 11 & 41.4 & 42.84 & 75.13 \\
\hline $7 \mathbf{a}$ & 17.74 (355) & 43.33 & 7.16 & 28.39 & 29.28 & 75.84 \\
\hline $7 \mathbf{b}$ & $19.00(365)$ & 53.61 & 9.99 & 42.91 & 44.06 & 76.89 \\
\hline
\end{tabular}

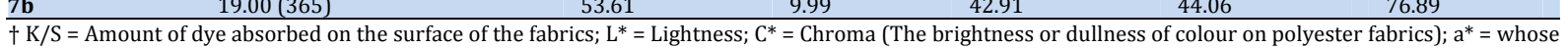
value represents the degree of redness (positive) and greenness (negative); $b^{*}=$ whose value represents the degree of yellowness (positive) and blueness (negative); $\mathrm{h}=$ Hue.

Table 2. Fastness properties of monoazo disperse dyes on polyester fabrics*.

\begin{tabular}{|c|c|c|c|c|c|c|c|c|c|c|c|}
\hline \multirow{3}{*}{$\begin{array}{l}\text { Dye } \\
\text { no }\end{array}$} & \multirow[t]{3}{*}{ Color shade on polyester } & \multirow{2}{*}{\multicolumn{3}{|c|}{ Wash fastness }} & \multicolumn{6}{|c|}{ Perspiration fastness } & \multirow[t]{3}{*}{ Light fastness } \\
\hline & & & & & \multicolumn{3}{|c|}{ Alkaline } & \multicolumn{3}{|c|}{ Acidic } & \\
\hline & & Alt & SC & SW & Alt & SC & SW & Alt & SC & SW & \\
\hline$\overline{6}$ & Yellowish-orange & 5 & 5 & 5 & 5 & 5 & 5 & 5 & 5 & 5 & 3 \\
\hline $7 a$ & Dark brown & 5 & 5 & 5 & 5 & 5 & 5 & 5 & 5 & 5 & 3 \\
\hline $7 \mathrm{~b}$ & brown & 5 & 5 & 5 & 5 & 5 & 5 & 5 & 5 & 5 & 3 \\
\hline
\end{tabular}

Table 3. Inhibition zone diameter of the tested arylhydrazonals and disperse dyes that showed strong antimicrobial activities against the tested microorganisms.

\begin{tabular}{|c|c|c|c|c|c|}
\hline \multirow[t]{2}{*}{ Compound no } & \multicolumn{5}{|c|}{ Inhibition zone diameter (Nearest $\mathbf{m m}$ ) $*$} \\
\hline & $\begin{array}{l}\text { B. subtilis } \\
\text { Mean } \pm \text { SD }\end{array}$ & $\begin{array}{l}\text { S. aureus } \\
\text { Mean } \pm S D\end{array}$ & $\begin{array}{l}\text { E. coli } \\
\text { Mean } \pm S D\end{array}$ & $\begin{array}{l}\text { P. aeruginosa } \\
\text { Mean } \pm \text { SD }\end{array}$ & $\begin{array}{l}\text { C. albicans } \\
\text { Mean } \pm \text { SD }\end{array}$ \\
\hline $2 a$ & $15.2 \pm 0.4$ & $13.4 \pm 0.5$ & $15.0 \pm 0.3$ & $15.8 \pm 0.4$ & $31.5 \pm 1.5$ \\
\hline $2 \mathrm{~b}$ & $12.8 \pm 0.5$ & $16.0 \pm 0.2$ & $17.8 \pm 1.2$ & $20.7 \pm 0.3$ & $33.0 \pm 0.7$ \\
\hline $2 c$ & $15.2 \pm 0.4$ & $13.4 \pm 0.5$ & $15.0 \pm 0.3$ & $15.8 \pm 0.4$ & $31.5 \pm 1.5$ \\
\hline 6 & $12.7 \pm 0.2$ & $11.7 \pm 0.4$ & $14.7 \pm 0.4$ & $16.1 \pm 0.5$ & $12.2 \pm 0.2$ \\
\hline $7 a$ & $0.7 \pm 0.7$ & - & $2.9 \pm 5.8$ & - & $13.4 \pm 0.4$ \\
\hline $7 \mathrm{~b}$ & $12.4 \pm 0.2$ & $12.3 \pm 0.3$ & $12.7 \pm 0.4$ & $13.0 \pm 0.5$ & $11.6 \pm 0.4$ \\
\hline Ampicillin & $15 \pm 1$ & $18.4 \pm 3.5$ & $18.6 \pm 1.3$ & $16.0 \pm 0.5$ & - \\
\hline Cyloheximide & - & - & - & - & - \\
\hline
\end{tabular}

*(-): No Inhibition; ampicillin: antibacterial $(100 \mathrm{mg} / \mathrm{mL})$; cycloheximide: antifungal $(100 \mathrm{mg} / \mathrm{mL}), \mathrm{SD}=$ Standard deviation.

It is believed that the pathways for these processes involve initial reaction of $\mathbf{2 b}, \mathbf{c}$ with ethyl cyanoacetate to yield the hydrazono-enone $\mathbf{3}$ that then cyclizes to generate the pyranimine 4. In the absence of ammonium ion, compound 4 undergoes a Dimroth type rearrangement to yield $\mathbf{7 a , b}$ (Scheme 2).

The disperse dyes $\mathbf{6}$ and 7a,b were applied to polyester fabrics at $2 \%$ (o.w.f) shade using high temperature dyeing method at $130{ }^{\circ} \mathrm{C}$. Color shades were obtained, varying from pale yellowish-orange to dark brown. The dyeing on the polyester fabrics was evaluated in terms of their fastness properties (e.g., fastnesses to washing, perspiration, and light). The optical measurements and fastness properties data for the dyed fabrics are listed in Tables 1 and 2. The color of dyeing on polyester fabrics is expressed in terms of CIELAB values (Table $1)$, and the following CIELAB coordinates were measured: lightness $\left(\mathrm{L}^{*}\right)$; chroma $\left(\mathrm{C}^{*}\right)$; hue angle $(\mathrm{h})$ from 0 to $360^{\circ}$; $\mathrm{a}^{*}$, whose value represents the degree of redness (positive) and greenness (negative); and $\mathrm{b}^{*}$, whose value represents the degree of yellowness (positive) and blueness (negative). A reflectance spectrophotometer was used for the colorimetric measurements of the dyed samples. The $K / S$ values given by the reflectance spectrometer were calculated at $\lambda_{\max }$ (wavelength of maximum absorption) and were directly correlated with the dye concentration on the dye substrate according to the Kubelka-Munk equation. In general, the positive values of $b^{*}$ (yellow-blue axis) indicated that the color hues of the arylazonicotinates disperse dyes $\mathbf{6}$ and $\mathbf{7 a , b}$ on the polyester fabric shifted to the yellowish directions.

The physical data for the dyed fabrics, given in (Table 2), shows that these disperse dyes displayed excellent washing and perspiration fastness and moderate light fastness levels.

The inhibition zone diameter data for the arylhydrazonals and disperse dyes, given in (Table 3), shows that all of the tested compounds showed strong positive antimicrobial activities against at least one of the tested microorganisms. All arylhydrazonals and disperse dyes show strong ability to inhibit the growth of Candida albicans which is appoint if observations that deserve further investigation.
Disperse dye 6 (Figure 1), arylhydrazonal $\mathbf{2 b}$ (Figure 2), and arylhydrazonal 2c (Figure 3), which showed the strongest inhibition zones among the five tested microbes, also all of these compounds showed cytolytic effect even after five days of incubation, there were no growth recorded in the inhibited zone for all five tested microbes.

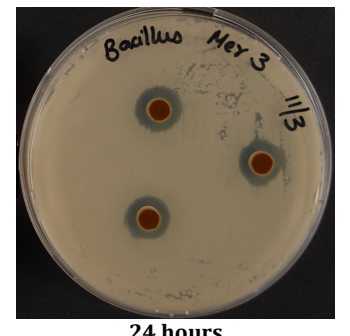

24 hours

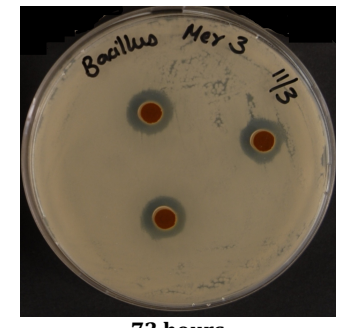

72 hours

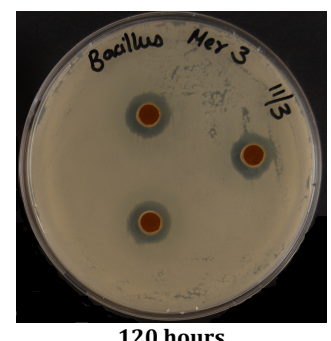

120 hours

Figure 1. Bacillus subtilus treated with $100 \mathrm{mg} / \mathrm{mL}$ of dye 6 after 24,72 , and 120 hours of incubation.

\section{Conclusion}

In conclusion, in the investigation described above, a series of arylazonicotinates disperse dyes were synthesized in a good yields via condensation of arylhydrazonals with cyanoacetate using microwave irradiation as an energy source. The dyed polyester fabrics, which display yellowish-orange to dark brown hues, were displayed excellent washing and 
perspiration fastness and moderate light fastness. Finally, the biological activities of the synthesized disperse dyes against Gram positive bacteria; Gram negative bacteria and yeast were discussed.

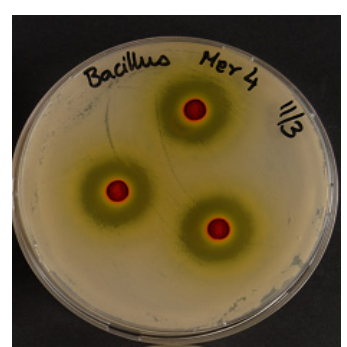

24 hours

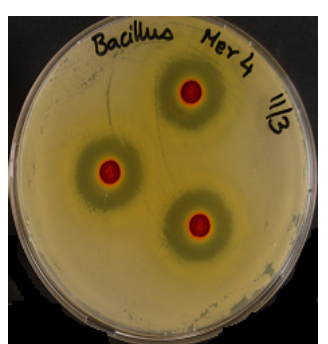

72 hours

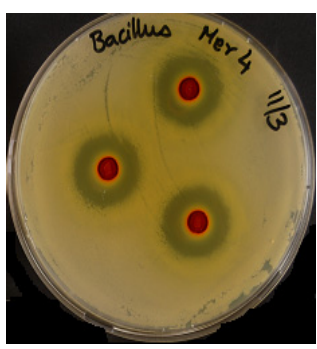

120 hours

Figure 2. Bacillus subtilus treated with $100 \mathrm{mg} / \mathrm{mL}$ of arylhydrazonal 2b after 24, 72, and 120 hours of incubation.

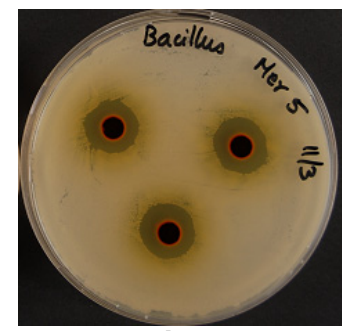

24 hours

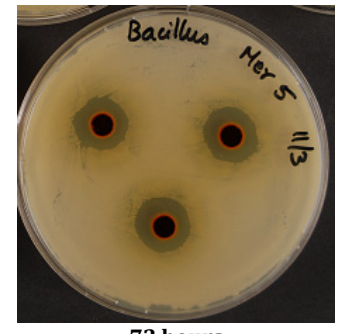

72 hours

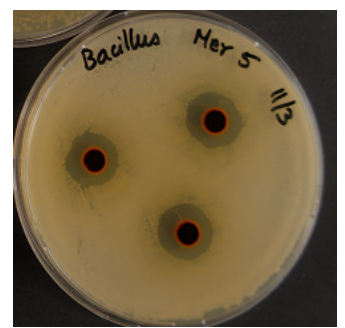

120 hours

Figure 3. Bacillus subtilus treated with $100 \mathrm{mg} / \mathrm{mL}$ of arylhydrazonal 2c after 24,72 , and 120 hours of incubation.

\section{Acknowledgements}

This research was done by the financial support of the Public Authority for Applied Education and Training (Transform grant TS-06-14) of Kuwait. Also authors are gratefully acknowledge and thankful to Prof. Saleh M. AlMousawi from chemistry department, faculty of science, Kuwait University for providing all necessary facilities to carry out the research work.

\section{References}

[1]. Al-Mousawi, S. M.; El-Apasery, M. A. Molecules 2012, 17, 6547-6556.
[2]. Al-Mousawi, S. M.; El-Apasery, M. A.; Mahmoud, H. M. Molecules 2012 17, 11495-11506.

[3]. Al-Etaibi, A. M.; El-Apasery , M. A.; Mahmoud H. M.; Al-Awadi, N. A Molecules 2012, 17, 4266-4280.

[4]. Malik, G. M.; Zadafiya, S. K. Der Chemica Sinica 2010, 1(3), 15-21.

[5]. Annen, O.; Egli, R.; Hasler, R.; Henzi, B.; Jakob, H.; Matzinger, P. Rev. Prog. Color. 1987, 17, 72-85.

[6]. El-Kashouti, M. A.; El Molla, M. M.; Elsayad, H. S.; Ahmed, K. A.; Helal M. H.; Elgemeie, G. H. Pigm. Resin. Technol. 2008, 37(2), 80-86.

[7]. Khan, M. K.; Abdul, M. J.; Shahnaz, P.; Rasheeda, P.; Moazzam, H. S. J. Chem. Soc. Pakistan 2010, 32, 505-510.

[8]. Rasheeda, P.; Shahnaz, P.; Ausaf; A.; Khan, K. M. Nat. Prod. Res. 2007 21, 7-12.

[9]. Lin, J. G.; Qiu, L.; Cheng, W.; Luo, S. N.; Wang, K.; Meng, Q. J. Inorg Chem. Commun. 2010, 13(7), 855-858.

[10]. Kim, K. R.; Rhee, S. D.; Kim, H. Y.; Jung, W. H.; Yang, S. D.; Kim, S. S Ahn, J. H.; Cheon, H. Eur. J. Pharm. 2005, 518(1), 63-70.

[11]. Mohanta, G. P.; Manna, P. K.; Manavalan, R. Indian J. Pharm. Sci. 2002, 64(5), 489-491.

[12]. El-Apasery, M. A.; Al-Mousawi, S. M.; Mahmoud, H.; Elnagdi, M. H. Int Res. J. Pure Appl. Chem. 2011, 1, 69-93.

[13]. Alnajjar, A.; Alsaiedi, M.; El-Apasery, M. A. Eur. J. Chem. 2013, 4(1), 5357.

[14]. Al-Mousawi, S. M.; El-Apasery, M. A.; Mahmoud, H.; Elnagdi, M. H. Int Res. J Pure Appl. Chem. , 2012, 2, 77-90.

[15]. Ashkar, S. M.; El-Apasery, M. A.; Touma, M. M.; Elnagdi, M. H. Molecules 2012, 17(8), 8822-8831.

[16]. Chrysler, L. P. Methods of Test for Color Fastness of Textiles and Leather, $7^{\text {th }}$ edition, Bradford, 1990, pp. 89-94.

[17]. Isaacson, D. M.; Kirschbaum, J. Assays of antimicrobial substances In Manual of Industrial Microbiology and Biotechnology (Demain, A. L.; Solomon, N. A.; Eds), ASM, 1986, pp. 410-435. 